\title{
Mona Garloff, Irenik, Gelehrsamkeit und Politik. Jean Hotman und der europäische Religionskonflikt um 1600
}

\section{Gérald Chaix}

\section{OpenEdition}

\section{Journals}

Édition électronique

URL : http://journals.openedition.org/ifha/8567

DOI : 10.4000 /ifha. 8567

ISSN : 2198-8943

Éditeur

IFRA - Institut franco-allemand (sciences historiques et sociales)

Référence électronique

Gérald Chaix, « Mona Garloff, Irenik, Gelehrsamkeit und Politik. Jean Hotman und der europäische

Religionskonflikt um 1600 », Revue de l'IFHA [En ligne], Date de recension, mis en ligne le 01 février 2017, consulté le 24 septembre 2020. URL : http://journals.openedition.org/ifha/8567 ; DOI : https://doi.org/ $10.4000 /$ ifha. 8567

Ce document a été généré automatiquement le 24 septembre 2020.

(C)IFHA 


\section{Mona Garloff, Irenik, Gelehrsamkeit und Politik. Jean Hotman und der europäische Religionskonflikt um 1600}

Gérald Chaix

\section{RÉFÉRENCE}

Mona Garloff, Irenik, Gelehrsamkeit und Politik. Jean Hotman und der europäische Religionskonflikt um 1600, Göttingen: V \& R unipress (Schriften zur politischen Kommunikation, 18), 2014, 400 p., $55 €$ 
Le titre et le sous-titre de cette Dissertation, préparée en cotutelle à Francfort-sur-le-Main et à Trente, en indiquent parfaitement l'objet et la problématique. Mona Garloff s'est focalisée sur le personnage de Jean Hotman (1552-1636). Mais il ne s'agit pas pour elle d'écrire la biographie de ce réformé. S'appuyant sur les écrits de l'érudit français, que son activité de diplomate a conduit en Angleterre, aux Pays-Bas et dans l'Empire, c'est aux conceptions et aux pratiques de l'irénisme qu'elle consacre son étude. «Bienheureux les pacifiques, car ils seront appellez enfans du Souverain » : c'est par cette péricope (Mt 5,9), citée par Hotman dans un manuscrit de 1607, que débute l'enquête. Il s'agit en premier lieu de comprendre ce qu'est l'irénisme - un
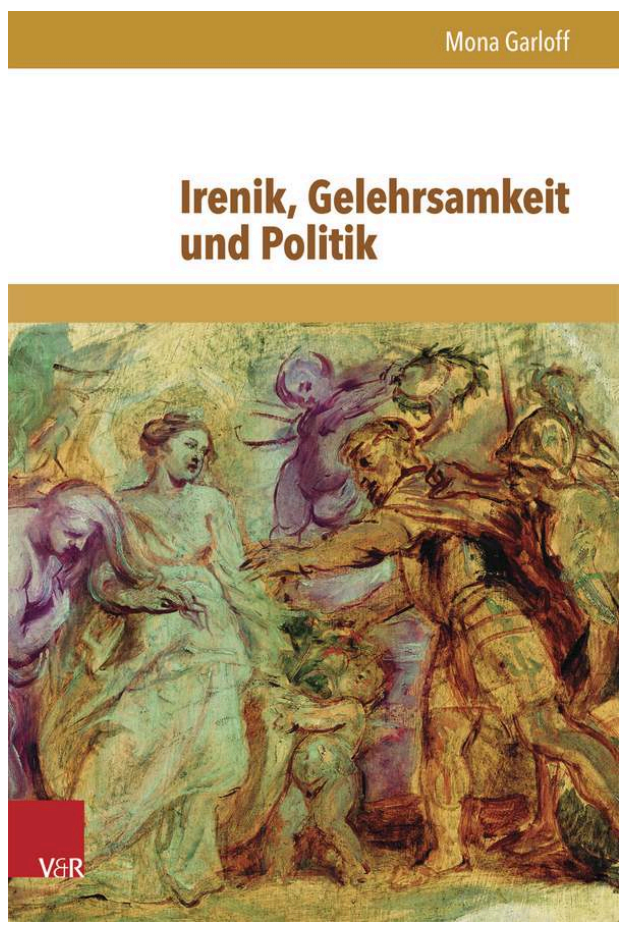
terme quelque peu anachronique, bien qu'il soit parfois utilisé par les contemporains - au tout début du XVII ${ }^{\mathrm{e}}$ siècle, entre concorde et tolérance. Et du même coup de situer Jean Hotman dans deux traditions : celle des colloques religieux qui se sont tenus dans l'Empire entre 1534 (Leipzig) et 1557 (Worms) et en France (Poissy, 1561), et celle qui a inspiré les édits de pacification dans le royaume de France, de 1562 (Saint-Germain) à 1577 (Poitiers).

L'auteure peut alors analyser comment les prises de position de Hotman s'articulent à la politique religieuse des années 1600. Face à la perspective de l'accession au trône du protestant Henri de Navarre, il est favorable, dans les années 1590, comme les gallicans, à la réunion d'un concile national. En 1592-1593, n'hésitant pas à critiquer la Réforme genevoise, il défend même l'idée d'une Église nationale et gallicane. Ce positionnement n'est pas sans conséquences au plan théologique. S'il rejette la conception sacrificielle de la messe défendue par les catholiques, il admet, contre Théodore de Bèze, l'idée de « la présence réelle de Jésus-Christ au saint sacrement de l'Eucharistie ». Pour Hotman, l'irénisme est une arme contre l'intransigeance, à commencer par celle manifestée, selon lui, par l'orthodoxie genevoise en général etpar Bèze en particulier. Il favorise au contraire la recherche d'une réconciliation des Églises que défendent, de manière très diverse, Antoine Lescaille, Nicolas Séguier ou encore Jean de Serres. Il permet de comprendre et même de justifier la conversion de Pierre Victor Palma-Cayet au lendemain de l'abjuration d'Henri IV, sans pour autant partager le zèle ultramontain du converti. L'édit de Nantes (1598), qu'il salue, tout comme Pierre de l'Estoile, JacquesAuguste de Thou ou Pierre de Belloy, n'est à ses yeux qu'une étape sur le chemin de la réunion des Églises. L'irénisme ne concerne d'ailleurs pas que la situation française. Hotman en discerne l'importance pour le royaume d'Angleterre. Il publie une traduction française du Basilikon Doron de Jacques $\mathrm{I}^{\mathrm{er}}$, dont il atténue les critiques à l'égard de l'Église romaine. De la même façon, il prend rapidement ses distances à l'égard du serment d'allégeance exigé de ses sujets par le souverain. Il s'agit d'éviter tout conflit avec Rome. Une attitude qui lui vaut la défiance du monarque anglais : 
Hotman ne parvient pas à se faire inviter à la cour. Il se garde pareillement de prendre parti dans le conflit qui oppose Rome et Venise, frappée d'interdit (1606-1607). L'opposition gallicane à la réception des décrets tridentins donne une nouvelle actualité à l'idée d'un concile national. Dans ce contexte, Hotman réédite la sélection de Sententiae "pour la paix de l'Église", que Melanchthon, Bucer et Hédion avaient rassemblée à l'intention de François I ${ }^{\mathrm{er}}$. L'initiative fut sévèrement jugée par les théologiens réformés. Dans une lettre adressée à Sully le 30 mars 1609, Hotman ne cache pas sa déception. L'irénisme ne lui en paraît pas moins nécessaire face aux tensions qui agitent l'Europe dans les premières décennies du XVII ${ }^{e}$ siècle et qui éclatent au grand jour durant la guerre de Trente Ans. Deux éditions du Syllabus - une anthologie de textes destinés à apaiser élans guerriers et controverses religieuses paraissent précisément en 1627 et 1628, soulignant leur actualité.

L'étude du Syllabus aliquot synodorum et colloquiorum, véritable "construction bibliographique d'un champ discursif irénique ", est ainsi l'objet de la troisième partie. La première version, réalisée à l'occasion de l'édition d'un ouvrage de Georg Cassander, rassemblait 62 ouvrages composés entre 1533 et 1607 . Adoptant le nouveau titre, la deuxième édition, publiée en 1628, passe à 161 ouvrages, parus entre 1522 et 1627 . Un an plus tard, la troisième édition atteint 175 ouvrages. Il s'agit d'une anthologie de loci communes iréniques. C'est le résultat d'un projet collectif placé sous le signe de l'humanisme tardif et porté par quelques membres de la "république des lettres »Grotius, Lingelsheim, Bernegger - héritiers d'Érasme, de Witzel et de Cassander. C'est aussi l'écho de l'Intérim (1548) et de la paix d'Augsbourg (1555) d'une part, des tentatives de réforme catholique d'autre part, depuis l'expérience colonaise (1536/1542-1543) jusqu'aux tentatives conduites en Pologne (1563), en passant par le Consilium de emendanda ecclesia (1537) et les décisions tridentines. La filiation avec les textes fondateurs du protestantisme - Confessio Augustana (1530), articles de Smalkalde (1537) - mais aussi avec la tradition irénique, que celui-ci n'ignore pas, est soulignée. Elle est d'ailleurs réaffirmée, au sein même du protestantisme, durant la guerre de Trente Ans. Mais l'irénisme peut aussi être à l'œuvre dans la présentation bienveillante, voire unificatrice, des différentes confessions chrétiennes et même du judaïsme. Il apparaît alors, plus que jamais, comme la résultante de la concorde et de la tolérance.

L'échec de l'irénisme, que traduisent les conflits du premier XVII ${ }^{e}$ siècle, ne justifie pas l'oubli de cette tradition. C'est ce qu'a parfaitement démontré M. Garloff dans un livre rigoureusement conduit et bien informé, où les citations sont reproduites en français, leur langue d'origine.

\section{INDEX}

Index chronologique : Période moderne

Thèmes : Histoire religieuse 


\section{AUTEURS}

\section{GÉRALD CHAIX}

Université François-Rabelais, Tours 